Communications in Physics, Vol. 26, No. 3 (2016), pp. 261-268

DOI:10.15625/0868-3166/26/3/8053

\title{
PREPARATION OF SERS SUBSTRATES FOR THE DETECTION OF ORGANIC MOLECULES AT LOW CONCENTRATION
}

\author{
TRAN THI KIM CHI ${ }^{1, \dagger}$, NGUYEN THI LE ${ }^{2}$, BUI THI THU HIEN ${ }^{1}$, DANG QUOC TRUNG ${ }^{1}$ \\ AND NGUYEN QUANG LIEM ${ }^{1}$ \\ ${ }^{1}$ Institute of Materials Science, Vietnam Academy of Science and Technology, \\ 18 Hoang Quoc Viet, Cau Giay, Hanoi, Vietnam \\ ${ }^{2}$ Cao Bang Teachers' Trainning College, De Tham, Cao Bang, Vietnam \\ ${ }^{\dagger} E$-mail: chittk@ims.vast.ac.vn \\ Received 04 April 2016 \\ Accepted for publication 10 August 2016
}

\begin{abstract}
We present the preparation of surface enhanced Raman spectroscopy (SERS) substrates by depositing silver nanoparticles (Ag NPs) onto the top of $1040 \mathrm{~nm}$ pores of porous silicon template produced by hydrofluoric acid $(H F)$ etching. The influences of the anodizing current density on the pore size were systematically investigated. The structural and textural characterization of the as-prepared SERS substrates were characterised by scanning electron microscope (SEM), $X$-ray diffraction (XRD), and Raman spectroscopy. The SERS activity was studied by Raman scattering spetra of Malachite Green (MG) molecules in water at room temperature. The SERS results showed an enhancement (20 times) by coupling of MG molecules with a localized surface plasmon resonance of $\mathrm{Ag}$ NPs. The limit of detection of MG molecules was determined to be $10^{-7} \mathrm{M}$.
\end{abstract}

Keywords: SERS, chemical etching, Raman, malachite green.

Classification numbers: $33.20 . \mathrm{Fb}, 73.20 . \mathrm{Mf}$.

\section{INTRODUCTION}

Surface-Enhanced Raman Spectroscopy (SERS) is a surface-sensitive technique that enhances the Raman scattering signal of analyte molecules adsorbed on rough metal surfaces. This enhancement factor is often observed $10^{4}-10^{6}$, and can be as high as $10^{8}$ to $10^{14}$ for some systems [1-4]. Therefore, SERS is considered as an effective technique for chemical and bioanalytical detection [2,3]. The enhanced Raman scattering can be explained in terms of electromagnetic and chemical mechanisms in the presence of metallic nanostructures such as silver $(\mathrm{Ag})$, gold $(\mathrm{Au})$, copper $(\mathrm{Cu})$, and aluminum $(\mathrm{Al})$ nanostructures [1-9]. Most accredited theories prove (C)2016 Vietnam Academy of Science and Technology 
that the electromagnetic mechanism is mainly responsible for the enhancement of Raman scattering due to the plasmon resonance created on surface of the nanostructured metal systems [5]. The plasmon resonance of $\mathrm{Ag}$ and $\mathrm{Au}$ colloidal nanoparticles (NPs) occurs in the visual wavelength range, therefore, they are the most widely used materials in the preparation of SERS substrates $[2,5,6,10-12]$. Besides, metal films with periodic structure evaporated on solid substrates exhibite controllable, reproducible and high surface-enhancement [13-17]. Recently, the utilization of templates with periodic porous structure for deposition of Ag or Au NPs is a promising approach to fabricate SERS substrate for regarding to the improvement of SERS efficiency [6].

In this work, we report the preparation of SERS substrates and the study of Raman scattering spectra of Malachite Green (MG) adsorbed on as-prepared substrate. These SERS substrates were prepared by the deposition of Ag NPs onto the porous silicon wafer which was treated by a chemical etching with hydrofluoric acid. The impact of the anodizing current density and the etching time on the pore size as well as the time of the Ag NPs deposition were studied. The SERS efficiency of prepared SERS substrates was estimated for MG molecules.

\section{EXPERIMENT}

\section{Chemicals and Characterization}

- Silicon (Si) wafer (single side polished), (100) orientation, p-type, resistivity $(0.01-0.018 \Omega \mathrm{cm})$ were purchased from Wako (Japan, LotNo. G124-017J).

- Hydrofluoric acid (HF), silver nitrate $\left(\mathrm{AgNO}_{3}\right)$, Malachite Green $(\mathrm{MG})$ were purchased from Xilong Chemical (China).

- The morphology of fabricated SERS active substrates was studied by Field Emission Scanning Electron Microscope - FE-SEM (S-4800, Hitachi, Japan,). The X-ray diffraction (XRD) patterns were recorded on a D8 (Bruker) using monochromatic $\mathrm{CuK}_{\alpha}$ radiation $(\lambda=1.53 \AA)$.

- Raman spectra of samples were recorded using a commercial (Jobin-Yvon LabRam) and home-made micro-Raman system (Horiba iHR550 high-resolution spectrometer equipped with a Hamamatsu cooled CCD and 532-nm laser as the excitation source).

\section{Preparation of SERS substrates}

SERS substrates were fabricated by two main steps: HF etching of p-type (100)-oriented Si wafer and deposition of Ag NPs onto the porous silicon.

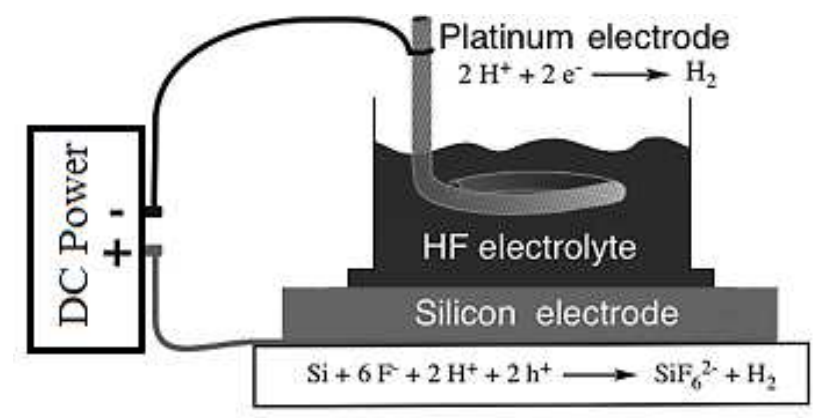

Fig. 1. Schematic of an electrochemical cell for producing porous $\mathrm{Si}$ wafer. 
- HF etching of (100)-oriented Si wafer to produce the nano porous silicon template was carry out according to the reported procedures [15-17] with some modifications in anodizing current density, etching time, and silicon wafer. The rougheness side of Si wafer was coated by a thick aluminum layer $(100 \mathrm{~nm})$ which prepared by sputtering and annealing at $450{ }^{\circ} \mathrm{C}$ for 120 minutes to obtain the Ohmic contact. The aluminum coated Si wafer was then used as a working electrode of an electrochemical cell with HF as electrolyte (Fig. 1). In this case, the working electrode acts as an anode, where an oxidation reaction takes place at its surface. The cathode electrode is platinum. The formation of porous structure is the results of the oxidation reaction at $\mathrm{Si}$ wafer surface. In the present work, a Teflon electrochemical cell was designed according to our etching conditions. This cell was filled with $10 \mathrm{~mL}$ of etching solution consisting of $48 \% \mathrm{HF}$ and ethanol. A silicon ( $\mathrm{Si})$ wafer $\left(1 \mathrm{~cm}^{2}\right.$ in area) and a Platinum $(\mathrm{Pt})$ grid $(2 \mathrm{~cm}$ in diameter) were used as the cathode and anode, respectively. The anodizing current density was changed from 25 to $150 \mathrm{~mA} . \mathrm{cm}^{-2}$ and the etching time was fixed as $5 \mathrm{~s}$.

- Deposition of Ag NPs into nanopores of porous silicon wafer. This process was carried out using a simple chemical method in that the porous silicon wafer was embedded in a mixture solution of $0.1 \mathrm{M} \mathrm{HF}$ and $\mathrm{AgNO}_{3}$ with different concentrations. Deposition time was varied between 10 and 20 minutes depending on the desired size of Ag NPs and the size of silicon wafer pores. After fabrication and thorough washing, the SERS substrates were stored in deionised water for further use.

\section{RESULTS AND DISCUSSION}

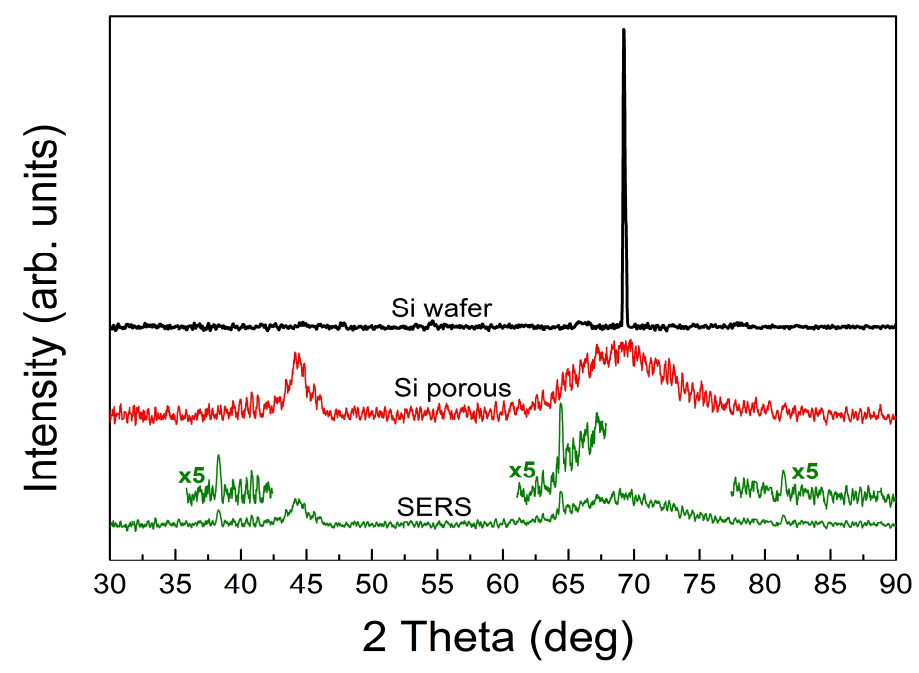

Fig. 2. XRD patterns of a (100)-oriented Si wafer (top), as-prepared porous silicon (middle) and SERS substrate (bottom). The XRD peaks of Ag NPs were magnified by factor of 5 .

Figure 2 shows the XRD patterns of the (100)-oriented Si wafer before and after HF etching, and of the SERS substrate prepared at anodizing current density of $100 \mathrm{~mA} \cdot \mathrm{cm}^{-2}$ and 10 minutes 
of Ag NPs depositing time. It is clearly seen that silicon wafer with (100) crystalline facet shows a peak at $2 \theta=69.26^{\circ}$, porous silicon shows a additional peak at $2 \theta=44.28^{\circ}$. For porous silicon, the X-ray diffraction peak around $2 \theta=69.26^{\circ}$ is broadened compared to that of thecrystalline silicon because of its porous nanostructures. The presence of Ag NPs on the surface of the porous silicon substrate was proved by the X-ray diffraction peaks at $2 \theta=38.32^{\circ}, 64.45^{\circ}$, and $81.46^{\circ}$. The X-ray diffraction peaks of Ag NPs are weak compared to those of silicon because the amount of $\mathrm{Ag}$ NPs is very small compared with silicon.


Fig. 3. SEM images of porous silicon samples prepared by HF etching of (100)-oriented $\mathrm{Si}$ wafer at different anodizing current densities: (a) $25 \mathrm{~mA} \cdot \mathrm{cm}^{-2}$, (b) $50 \mathrm{~mA} \cdot \mathrm{cm}^{-2}$, (c) $100 \mathrm{~mA} . \mathrm{cm}^{-2}$, and (d) $150 \mathrm{~mA} . \mathrm{cm}^{-2}$ for 5 seconds etching time.

Figure 3 shows the SEM images of porous silicon samples obtained by HF etching with different anodizing current densities. The results show that the uniform porous silicon structure was formed under all applied anodizing current densities. The pore size is a linear function of the anodizing current density: $10 \mathrm{~nm}, 15 \mathrm{~nm}, 30 \mathrm{~nm}$ and $40 \mathrm{~nm}$ corresponding to the anodizing current 
densities as $25 \mathrm{~mA} . \mathrm{cm}^{-2}, 50 \mathrm{~mA} \cdot \mathrm{cm}^{-2}, 100 \mathrm{~mA} \cdot \mathrm{cm}^{-2}$ and $150 \mathrm{~mA} \cdot \mathrm{cm}^{-2}$ (Fig. 3). However, the sample having the most homogenous pores was obtained under $100 \mathrm{~mA} . \mathrm{cm}^{-2}$ anodizing current density. Therefore, this current density was used in the next depositions. In Fig. 4, it is clear that the $\mathrm{Ag}$ NPs are fotmed in the pores at $1 \mathrm{mM} \mathrm{AgNO}$. The $\mathrm{AgNO}_{3}$ become clusters on the top of pore when the $\mathrm{AgNO}_{3}$ concentration increases ( 2 and $3 \mathrm{nM}$ ). The clusters shrink to spheroid NPs at $5 \mathrm{mM} \mathrm{AgNO}$. The $\mathrm{Ag} \mathrm{NPs}$ were deposited on the porous silicon by in situ reduction of $\mathrm{AgNO}_{3}$ in acidic media (0.1M HF) for 10 minutes. The obtained substrates were annealed at $500^{\circ}$ for 30 minutes in ambient.

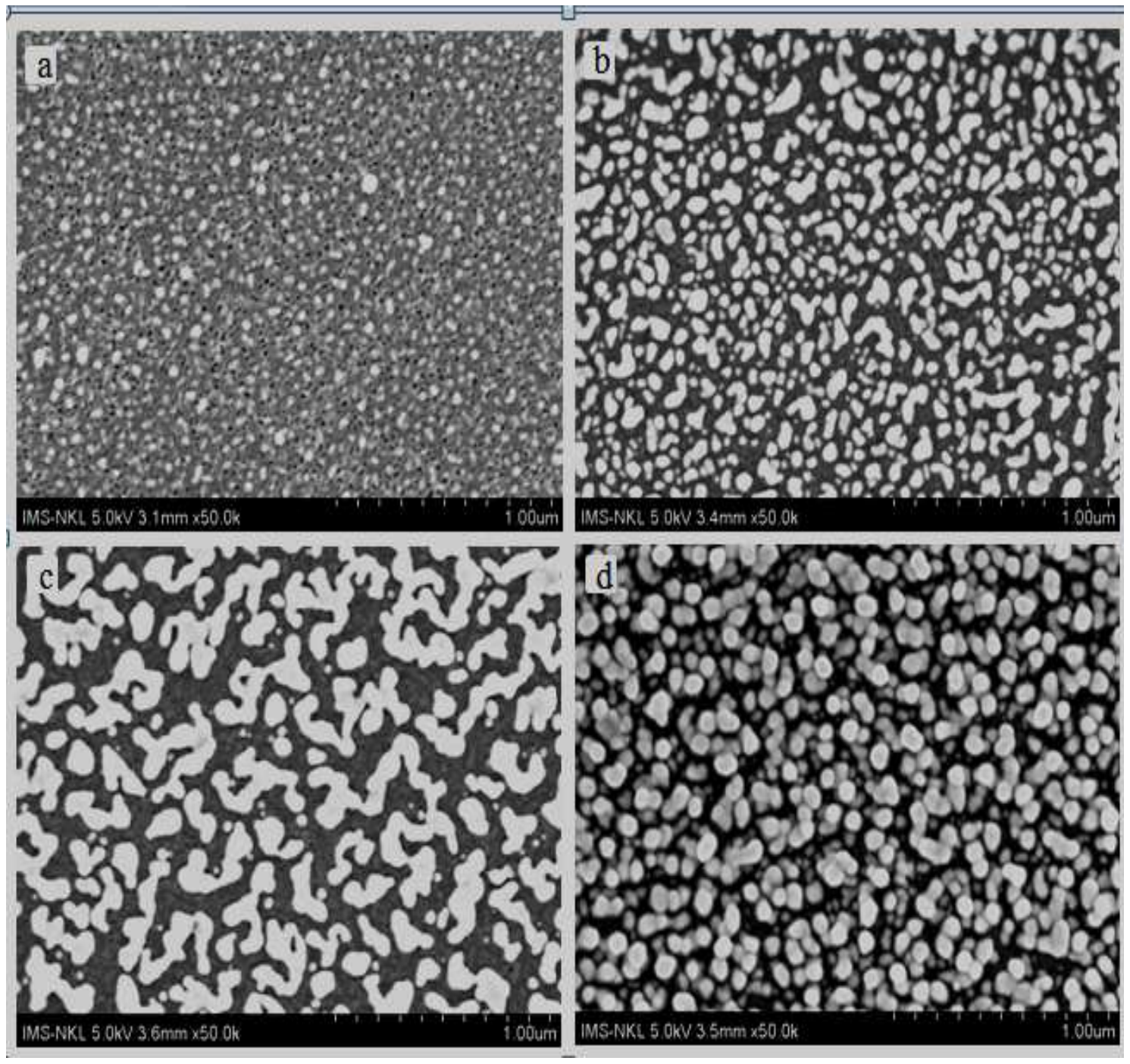

Fig. 4. SEM images of fabricated SERS substrates at different $\mathrm{AgNO}_{3}$ concentrations: (a) $1 \mathrm{mM}$, (b) $2 \mathrm{mM}$ (c) $3 \mathrm{mM}$, and (d) $5 \mathrm{mM} \mathrm{AgNO}_{3}$. Deposition time is 10 minutes. 
The SERS effect of the fabricated substrates was studied by the Raman spectra of Malachite Green (MG) in water. $10 \mu \mathrm{L}$ of aqueous MG solutions with different concentrations were dropped onto the as-prepared SERS substrates and dried before measurement. The spreading area is $\sim 1 \times 1 \mathrm{~cm}^{2}$.

Figure 5 shows the Raman spectra of MG solution dropped on a $\mathrm{Si}$ wafer and the asprepared SERS substrate. The characteristic Raman peaks of MG were clearly observed in the high-frequency region $[18,19]$. Namely, the strong Raman band belonging to $\mathrm{N}-\mathrm{C}$ bonding and $\mathrm{C}-\mathrm{C}$ stretching vibrations was obsvered at $1617 \mathrm{~cm}^{-1}$. The bands at $1171 \mathrm{~cm}^{-1}$ and $1294 \mathrm{~cm}^{-1}$ can be assigned to the aromatic $\mathrm{C}-\mathrm{H}$ in-plane bending vibrations; and $1366 \mathrm{~cm}^{-1}$ can be ascribed to the $\mathrm{N}-\mathrm{C}$ stretching vibration coupled with the $\mathrm{C}-\mathrm{C}$ and $\mathrm{C}-\mathrm{H}$ in-plane motions at $1394 \mathrm{~cm}^{-1}$. The band appeared at $914 \mathrm{~cm}^{-1}$ can be attributed to the ring skeletal radial vibration. Compared to the spectrum of MG dropped onto Si wafer, a remarkable increase in intensity of the active Raman peaks (20 times) proves the plasmon resonance-assisted effect exhibited by the presence of Ag NPs

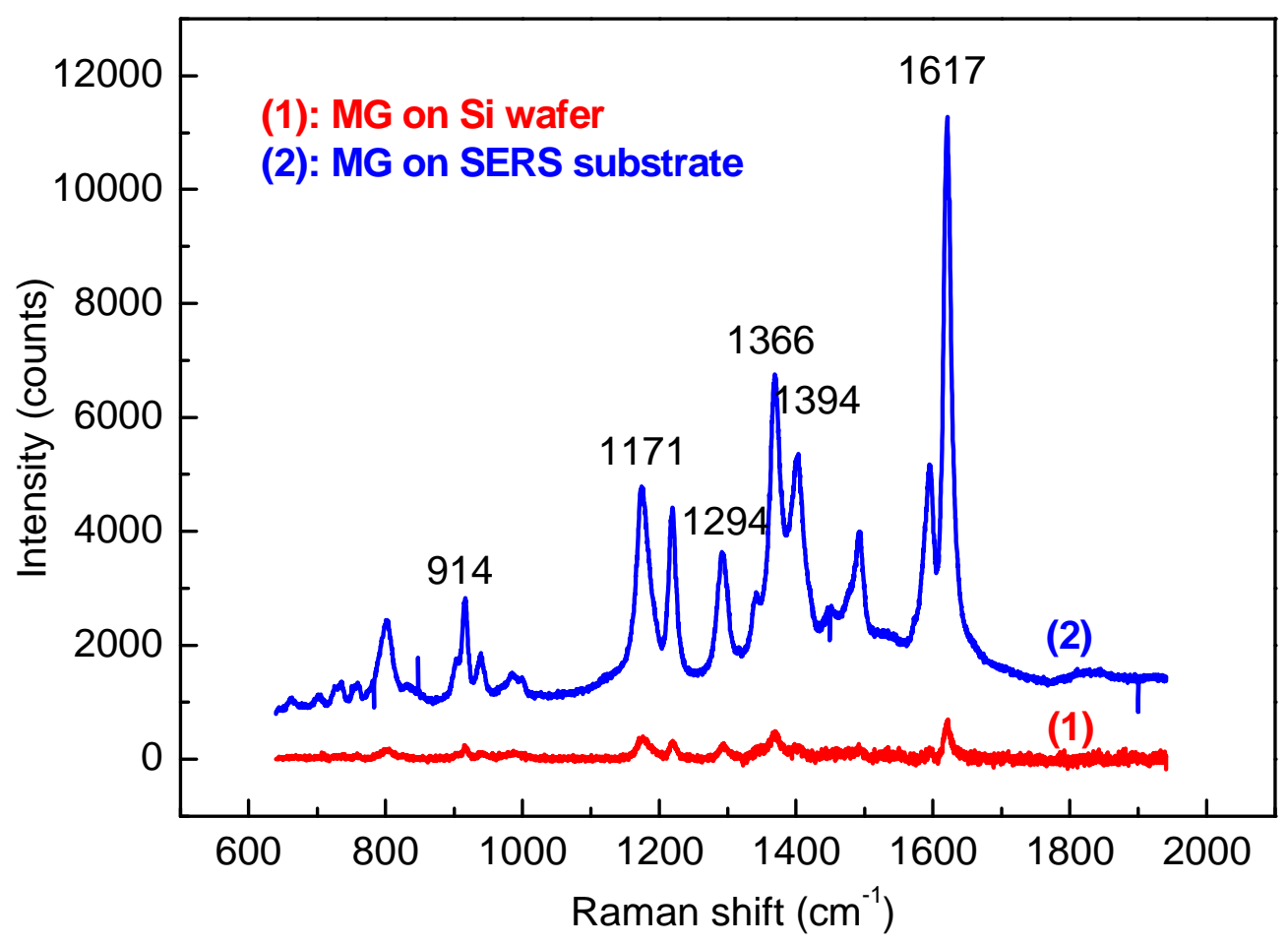

Fig. 5. Raman spectra of Malachite Green of concentration: $2 \times 10^{-5} \mathrm{M}$ dropped onto (1) $\mathrm{Si}$ wafer and (2) SERS substrate prepared at $2 \mathrm{mM} \mathrm{AgNO}_{3}$.

Figure 6 shows the Raman spectra of MG molecules at $10^{-5}, 10^{-6}$ and $10^{-7} \mathrm{M}$ dropped onto the SERS substrate of $2 \mathrm{mM} \mathrm{AgNO}_{3}$ deposition. It is clearly seen that the Raman scattering signal is increased with the MG concentration and SERS substrate can be used to detect MG molecules at concentration as low as $10^{-7} \mathrm{M}$. 


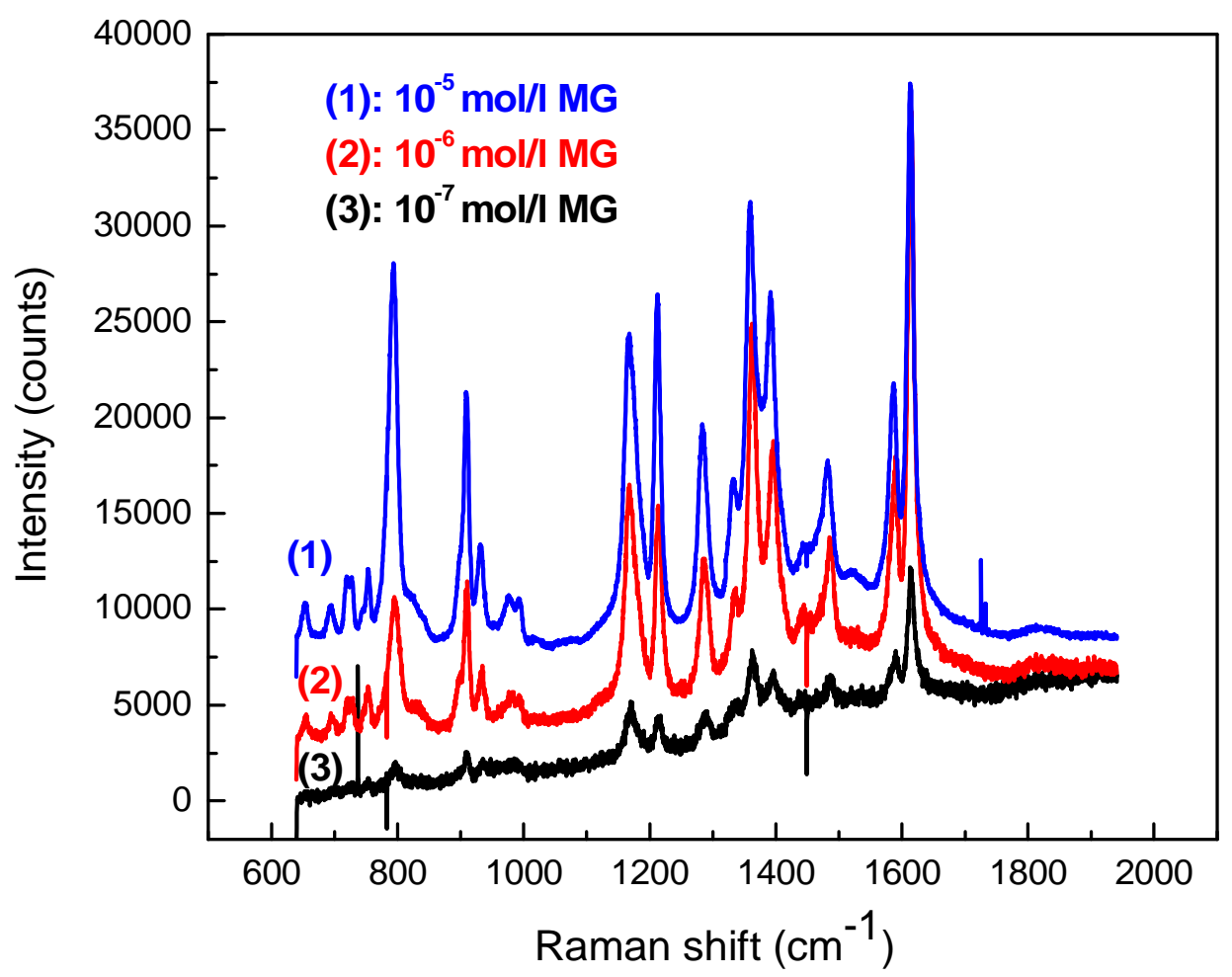

Fig. 6. Raman spectra of MG with various concentrations (1) $10^{-5} \mathrm{M}$ (2) $10^{-6} \mathrm{M}$, and (3) $10^{-7} \mathrm{M}$ dropped onto the SERS substrate of $2 \mathrm{mM} \mathrm{AgNO}_{3}$ deposition.

\section{CONCLUSION}

The SERS substrates were successfully fabricated by deposition of Ag NPs onto the porous silicon template by in situ reduction of $\mathrm{AgNO}_{3}$ in $0.1 \mathrm{M}$ HF. The porous silicon structure was formed by anodization HF etching the low resistivity p-type (100) silicon wafers. The pore size increases with increasing the anodizing current density. Especially, the silicon template with uniform pore size distribution was obtained at the anodizing current density of $100 \mathrm{~mA} . \mathrm{cm}^{-2}$. The fabricated SERS substrates were used to detect MG molecules and the limit of detection was determined to be $10^{-7} \mathrm{M}$.

\section{ACKNOWLEDGMENS}

This work was supported by Ministry of Science and Technology (e-ASIA Project No.33/2013/HD-NDT) and Vietnam Academy of Science and Technology (VAST.ĐL.06/13-14). We thank National Key Laboratory for Electronic Materials and Devices (VAST/IMS) for the use of facilities. 


\section{REFERENCES}

[1] U. K. Sur and J. Chowdhury, Curr. Sci 105 (2013) 923.

[2] B. Sharma, R. R. Frontiera, A.-I. Henry, E. Ringe and R. P. Van Duyne, Materials Today 15 (2012) 16.

[3] M. Fan, G. F. Andrade and A. G. Brolo, Anal. Chim. Acta 693 (2011) 7.

[4] S. Daniel, Improved performance of reduced silver substrates in surface enhanced raman scattering, Master's thesis, University of Eastern Finland, 2013.

[5] G. M. Herrera, A. C. Padilla and S. P. Hernandez-Rivera, Nanomaterials 3 (2013) 158.

[6] L. A. Dick, A. J. Haes and R. P. Van Duyne, J. Phys. Chem. B 104 (2000) 11752.

[7] A. M. Michaels, J. Jiang and L. Brus, J. Phys. Chem. B 104 (2000) 11965.

[8] S.-P. Chen, C. M. Hosten, A. Vivoni, R. L. Birke and J. R. Lombardi, Langmuir 18 (2002) 9888.

[9] J. R. Lombardi, R. L. Birke, T. Lu and J. Xu, J. Chem. Phys. 84 (1986) 4174.

[10] T. Q. N. Luong, T. A. Cao and T. C. Dao, Adv. Nat. Sci.: Nanosci. Nanotechnol. 4 (2013) 015018.

[11] T. C. Dao, T. Q. N. Luong, T. A. Cao, N. H. Nguyen, N. M. Kieu, T. T. Luong and V. V. Le, Adv. Nat. Sci.: Nanosci. Nanotechnol. 6 (2015) 035012.

[12] T. C. Dao, T. Q. N. Luong, T. A. Cao, N. M. Kieu et al., Adv. Nat. Sci.: Nanosci. Nanotechnol. 7 (2016) 015007.

[13] C. L. Haynes, A. D. McFarland, M. T. Smith, J. C. Hulteen and R. P. Van Duyne, J. Phys. Chem. B 106 (2002) 1898.

[14] Y. Jiao, D. S. Koktysh, N. Phambu and S. M. Weiss, Applied Physics Letters 97 (2010) 153125.

[15] H. Lin, J. Mock, D. Smith, T. Gao and M. J. Sailor, J. Phys. Chem. B 108 (2004) 11654.

[16] F. Giorgis, E. Descrovi, A. Chiodoni, E. Froner, M. Scarpa, A. Venturello and F. Geobaldo, Appl. Surf. Sci. 254 (2008) 7494.

[17] J. N. G. Bugayong, Electrochemical etching of isolated structures in p-type silicon, Ph.D. thesis, University of the Philippines at Los Baños, 2011.

[18] B. Pettinger, B. Ren, G. Picardi, R. Schuster and G. Ertl, J. Raman Spectrosc. 36 (2005) 541.

[19] Y. Zhao, Y. Tian, P. Ma, A. Yu, H. Zhang and Y. Chen, Anal. Methods 7 (2015) 8116. 